of people with a trait in common also share certain SNPs, chances are that the SNPs are related in some way to that characteristic.

The researchers split their study participants into two groups - those who reported having had sex with someone of the same sex, and those who didn't. Then the researchers performed two separate analyses. In one, they evaluated more than one million SNPs and looked at whether people who had more SNPs in common with each other also reported similar sexual behaviours. The scientists found that genetics could explain $8-25 \%$ of the variation in sexual behaviour.

For their second analysis, Ganna and his colleagues wanted to see which particular SNPs were associated with same-sex sexual behaviours, and found five that were more common among individuals in that group. However, those five SNPs collectively explained less than $1 \%$ of the variation in sexual behaviour.

This suggests that there are a lot of genes that influence sexual behaviour, many of which researchers haven't found yet, says Ganna. An even larger sample size could help to identify those missing variants, he says.

But Ganna cautions that these SNPs can't be used to reliably predict sexual preferences in any individual, because no single gene has a large effect on sexual behaviours.

\section{IT'S COMPLICATED}

Although the researchers have identified some of the SNPs involved in same-sex sexual behaviour, they aren't sure what the variants do. One is near a gene related to smell, which Ganna says has a role in sexual attraction. Another SNP is associated with male-pattern baldness - a trait influenced by levels of sex hormones, which suggests that these hormones are also linked to same-sex sexual behaviour.

The results demonstrate the complexity of human sexuality, says Ganna. They also presented a challenge to the researchers, who knew that explaining nuanced findings on such a sensitive topic would be tricky.

To ensure that their results are not misinterpreted, the study researchers worked with LGBTQ advocacy groups and sciencecommunication specialists on the best way to convey their findings in the research paper and to the public. Their efforts included the design of a website that lays out the results - and their limitations - to the public, using sensitive, jargon-free language (https://geneticsexbehavior.info/).

Ewan Birney, a geneticist and director of the EMBL European Bioinformatics Institute near Cambridge, UK, applauds that effort.

Although some researchers and LGBTQ advocates might question the wisdom of conducting this kind of research, Birney says that it's important. There has been a lot of sociological research on same-sex sexual behaviour, he says, but this is a complicated topic. It's time to bring a strong, biologically based perspective to the discussion, Birney says.

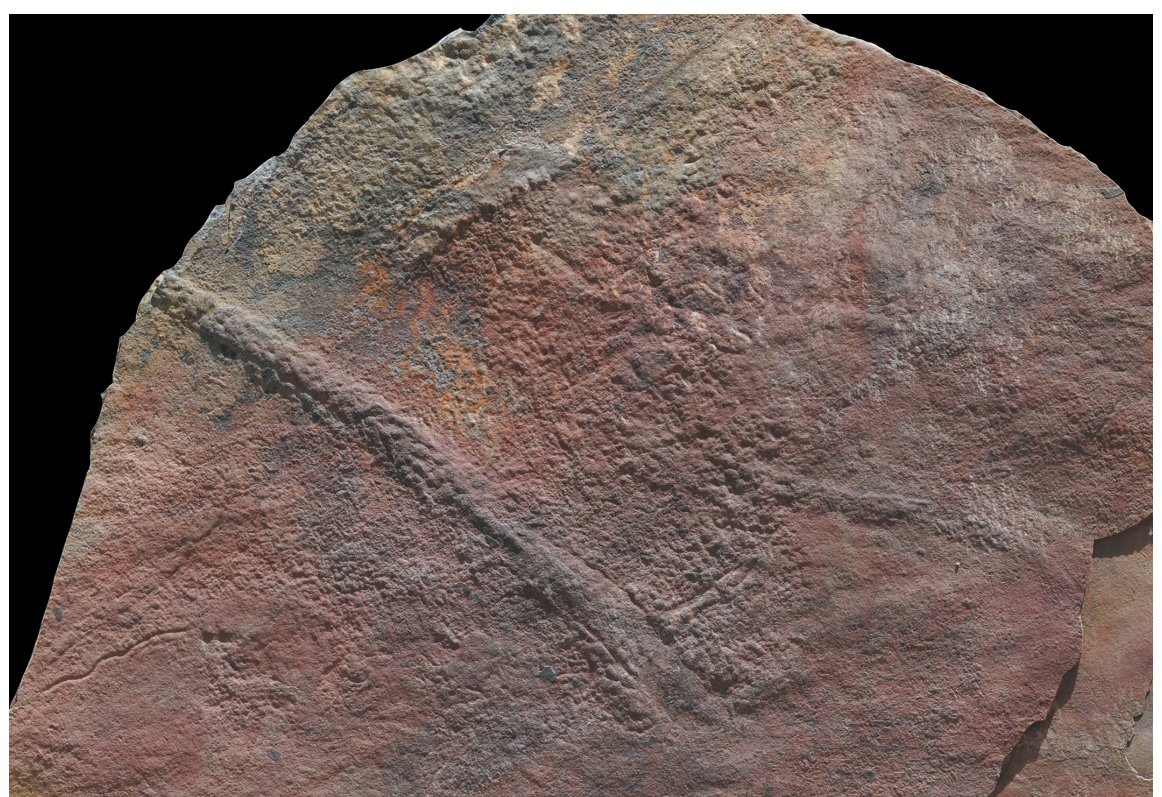

A fossil of Yilingia spiciformis and the track it left as it moved.

\section{EVOLUTION}

\section{Worm fossil recasts origins of animal life}

\section{BY COLIN BARRAS}

$\mathrm{M}$ ore than half a billion years ago, a strange, worm-like creature died as it crawled across a muddy sea floor. Both the organism and the trail it left in its wake lay undisturbed for so long that they fossilized. Now, they are helping us to revise our understanding of when and how animals evolved.

The fossil, which formed some time between 551 million and 539 million years ago, in the Ediacaran period, joins a growing body of evidence that challenges the idea that animal life burst onto the scene in an event known as the Cambrian explosion, which began about 539 million years ago. An analysis of the fossil, which was found in southern China and has been named Yilingia spiciformis, is published in Nature (Z. Chen et al. Nature https://doi.org/10.1038/s41586019-1522-7; 2019).

"It is just pushing things further and further back into the Ediacaran," says Rachel Wood, a geoscientist at the University of Edinburgh, UK. The Cambrian explosion no longer appears to be such an abrupt event in the history of life on Earth, she says.

The rock record has already revealed that the Ediacaran seas were rich in life, but many fossils from the period have strange anatomical features unlike those seen in modern animals. Palaeontologists have struggled to relate the Ediacaran organisms to the creatures of the Cambrian, which bolstered the idea that the Cambrian explosion represented the dramatic first appearance of familiar animals.

But opinions have begun to shift. Some Ediacaran organisms have been recognized as animals despite their peculiar anatomy, suggesting that animal life began millions of years before the Cambrian explosion (I. Bobrovskiy et al. Science 361, 1246-1249; 2018).

Yilingia spiciformis fits into that picture, and helps push the idea further. The animal grew up to 27 centimetres long and 2.5 centimetres wide. With a segmented body that is symmetrical down its length, it has an anatomy that is more obviously similar to that of Cambrian animals, says Shuhai Xiao, a palaeontologist at Virginia Tech in Blacksburg and a member of the research team that found and analysed the fossils.

"In the past, palaeontologists emphasized the differences between the Ediacaran and Cambrian," says Xiao. "But when you think about it, life had to continue through the boundary. Some lineages had to survive." - 